\title{
Fatores ambientais que geram risco à saúde pública no município de Capão do Leão/RS
}

\author{
Environmental factors that trigger risk to health in the city of Capão do Leão/RS
}

\author{
Gabrieli da Cunha Pereira ${ }^{1}$, Aline Cristina Calçada de Oliveira ${ }^{2}$ \\ 'Gestora Ambiental. Acadêmica do Curso de Especialização em Gestão Ambiental em Municípios - FURG - RS - Brasil. \\ 2Professora Assistente da Escola de Enfermagem, FURG. Mestre em Educação Ambiental - FURG - RS - Brasil.
}

\begin{abstract}
Resumo
A existência de condições adequadas de saneamento é requisito indispensável para a proteção da saúde humana, assim como medida fundamental para a proteção do ambiente. No Brasil as doenças resultantes da falta ou inadequação de saneamento, especialmente em áreas pobres, têm agravado o quadro epidemiológico. No Rio Grande do Sul, dos 496 municípios apenas $41 \%$ tem rede coletora de esgoto, e uma fatia menor ainda trata o esgoto coletado: $15 \%$. Neste contexto está o município de Capão do Leão, onde, o abastecimento de água potável é realizado pela concessionária estadual e o esgoto é coletado em rede mista sem tratamento final. Este estudo se justifica como ferramenta de gestão no auxílio à construção de um ambiente saudável no município de Capão do Leão, e teve como objetivo realizar um levantamento das doenças relacionadas a fatores ambientais que acometeram a população de Capão do Leão nos anos de 2010, 2011 e 2012, além de traçar um panorama da atual situação do saneamento ambiental no município e diagnosticar os principais fatores ambientais que podem ocasionar problemas de saúde à população que nele reside. Por meio da análise dos dados obtidos, conclui-se que a população de Capão do Leão está exposta, principalmente, a zoonoses e doenças relacionadas às excretas e de transmissão via feco-oral. Foi possível verificar que, assim como na maioria dos municípios brasileiros, em Capão do Leão o saneamento ambiental ainda está distante do ideal, pois faltam itens de infraestrutura para a prevenção de doenças relacionadas a fatores ambientais. O Plano de Saneamento Básico Municipal já foi estruturado, o que deve contribuir para avanços no saneamento ambiental nos próximos anos.
\end{abstract}

Palavras-chave: Percepção Ambiental, Educação Ambiental, Educação Inclusiva, João Pessoa.

\begin{abstract}
The existence of adequate sanitation is an essential requirement for the protection of human health, as well as critical to environmental protection measure. In Brazil the diseases resulting from lack or inadequacy of sanitation, especially in poor areas, have compounded the epidemiological picture. In Rio Grande do Sul, from the 496 cities, only $41 \%$ have sewage disposal system, and a smaller slice still treats collected sewage: $15 \%$. In this context lies the city of Capão do Leão, where the supply of potable water is provided by a state company and sewage is collected in mixed network without final treatment. This study is justified as a management tool in helping to build a healthy environment in the city of Capão do Leão, and aimed to survey the diseases related to environmental factors that affected the population of Capão do Leão in the years 2010, 2011 and 2012, as well as to give an overview of the current status of environmental sanitation in the city and diagnose the main environmental factors that can cause health problems to the local people. Through the analysis of the data obtained, it is concluded that the population of Capão do Leão is mainly exposed to zoonosis, excreta-related diseases and diseases via fecal-oral transmission. We found that, like in most cities, in Capão do Leão environmental sanitation is still far from ideal, as it lacks infrastructure items for the prevention of diseases related to environmental factors. The Local Sanitation Plan has been structured, which must contribute to advances in environmental sanitation in the coming years.
\end{abstract}

Key words : Environmental Sanitation, zoonosis prevention measures. 


\section{INTRODUÇ̃̃O}

A importância do saneamento é reconhecida por vários autores e corroborada em diversos estudos. A existência de condições adequadas de saneamento é requisito indispensável para a proteção da saúde humana, assim como medida fundamental para a proteção do ambiente; satisfaz necessidades de conforto às populações e é elemento indissociável do planejamento e desenvolvimento sustentável nos meios urbano e rural (BRASIL, 2006).

O conceito de saneamento pode ser entendido segundo uma visão de intervenção sobre o meio físico onde o homem vive, se reproduz e desenvolve suas atividades produtivas. Logo, saneamento compreende um conjunto de ações sobre o meio ambiente no qual vivem as populações, visando garantir a elas condições de salubridade, que protejam a sua saúde, dado que saúde, na definição da Organização Mundial da Saúde, seria o "estado de completo bem estar físico, mental ou social, e não somente a ausência de doenças" (BRASIL, 2006).

No Manual de Saneamento da Fundação Nacional de Saúde - FUNASA (BRASIL, 2007), saneamento ambiental é definido como "o conjunto de ações socioeconômicas que têm por objetivo alcançar Salubridade Ambiental, por meio de abastecimento de água potável, coleta e disposição sanitária de resíduos sólidos, líquidos e gasosos, promoção da disciplina sanitária de uso do solo, drenagem urbana, controle de doenças transmissíveis e demais serviços e obras especializadas, com a finalidade de proteger e melhorar as condições de vida urbana e rural", sendo a Salubridade Ambiental "o estado de higidez em que vive a população urbana e rural, tanto no que se refere a sua capacidade de inibir, prevenir ou impedir a ocorrência de endemias ou epidemias veiculadas pelo meio ambiente, como no tocante ao seu potencial de promover o aperfeiçoamento de condições mesológicas ${ }^{1}$ favoráveis ao pleno gozo de saúde e bem-estar", ainda segundo o mesmo manual.

O conceito de Promoção de Saúde proposto pela Organização Mundial de Saúde, desde a Conferência de Ottawa, em 1986, é visto como o princípio orientador das ações de saúde em todo o mundo. Assim sendo, parte-se do pressuposto de que um dos mais importantes fatores determinantes da saúde são as condições ambientais (BRASIL, 2010).

1. Que se relaciona a mesologia (condições do meio ambiente). Fonte: http://www.dicio.com.br/
A utilização do saneamento como instrumento de promoção da saúde pressupõe a superação dos entraves políticos e gerenciais que têm dificultado a extensão dos benefícios aos residentes em áreas rurais, municípios e localidades de pequeno porte.

As melhorias sanitárias introduzidas no País desde o início do século XX contribuíram efetivamente para a redução e mesmo erradicação de várias doenças. Mesmo assim, as doenças relacionadas a condições precárias de vida continuam a representar um papel significativo no quadro de morbi-mortalidade da população, apesar de serem, em sua maioria, evitáveis ou mesmo erradicáveis (BRASIL, 2010).

No Brasil, as doenças resultantes da falta ou inadequação de saneamento, especialmente em áreas pobres, têm agravado o quadro epidemiológico. Doenças como cólera, dengue, esquistossomose e leptospirose são exemplos disso. Segundo a FUNASA, atualmente, cerca de $90 \%$ da população urbana brasileira é atendida com água potável e $60 \%$ com redes coletoras de esgotos. O déficit, ainda existente, está localizado, basicamente, nos bolsões de pobreza, ou seja, nas favelas, nas periferias das cidades, na zona rural e no interior (BRASIL, 2006).

Na Região Sul do país, segundo dados da Pesquisa Nacional de Saneamento Básico, realizada pelo IBGE em 2008, 99,7\% dos municípios contam com serviço de abastecimento de água por rede geral de distribuição. Mas quando se trata de coleta e tratamento de esgotos, a realidade é outra. No Rio Grande do Sul, dos 496 municípios apenas $41 \%$ tem rede coletora de esgoto, e uma fatia menor ainda trata o esgoto coletado: $15 \%$ (IBGE, 2011).

Neste contexto está o município de Capão do Leão, com 24.298 habitantes (IBGE, 2010), localizado na metade sul do Estado do Rio Grande do Sul, onde, segundo o Plano Municipal de Saneamento Básico o abastecimento de água potável é realizado pela concessionária estadual - CORSAN, e o esgotamento sanitário é formado por sistemas unitários residenciais e comerciais, com alguns pontos coletados em rede mista sem tratamento final.

Assim, este é um estudo cuja proposta foi abordar os fatores ambientais que geram risco à saúde pública no munícipio de Capão do Leão/RS.

\section{I.I. Justificativa}

Para a existência de um meio ambiente saudável faz-se necessário o reconhecimento dos agentes e fatores de risco que possam interferir na 
complexidade dos sistemas ambientais e humanos. Mais importante ainda é compreender que há uma relação intrínseca e recíproca entre os fatores determinantes da saúde ambiental e o processo de construção da saúde humana (FILHO et al., 2010, p. 188).

Sendo assim, este estudo se justifica como ferramenta de gestão no auxílio à construção de um ambiente saudável no município de Capão do Leão, que ainda possui recursos e infraestrutura limitada.

\section{OBJETIVOS}

\section{I.I. Objetivo Geral}

Diagnosticar os principais fatores ambientais presentes no município de Capão do Leão/ RS que podem ocasionar problemas de saúde à população que nele reside.

\subsubsection{Objetivos Específicos}

Realizar um levantamento das doenças relacionadas a fatores ambientais que acometeram a população de Capão do Leão nos anos de 2010, 2011 e 2012, por meio das notificações recebidas pela Vigilância Epidemiológica de Capão do Leão/ RS e traçar um panorama da atual situação do saneamento ambiental no município.

\section{REVISÃO BIBLIOGRÁFICA}

\section{Fatores Ambientais e Saúde}

Segundo PHILIPPI JR. (2004) a abordagem multidisciplinar da questão ambiental exige conhecimentos de diversas disciplinas que têm como preocupação o meio ambiente. Esses conhecimentos devem estar implicitamente inter-relacionados, promovendo um melhor entendimento das reações fenomenológicas de causa e efeito contínuas, sequenciais e retroativas presentes na natureza.

Por essa razão, os conceitos de saúde, saneamento e saúde pública vêm sofrendo um processo de convergência conceitual dentro de sua evolução histórica (PHILIPPI JR. et al., 2004).

O esforço para a incorporação da variável ambiental no movimento dos indicadores sociais teve início na década de 60 e se ampliou nos anos 70. Nos últimos 20 anos, verificou-se um aumento do interesse por esta temática, tendo-se conhecimento da formação de grupos nacionais e internacionais preocupados com esta questão (BORJA e MORAES, 2003).

O enfoque tradicional da saúde pública, hoje, se combina com os conceitos da interdependência da saúde com os fatores ambientais (saúde ambiental), e esse novo enfoque reconhece que, em princípio, quase todos os aspectos do meio ambiente afetam potencialmente a saúde. Isto é verdadeiro não só para agentes específicos, como microrganismos ou outras entidades biológicas, forças ou agentes físicos e químicos, mas também para elementos dos meios urbano e rural: casas, locais de trabalho, áreas de lazer, infraestruturas, indústrias (BRILHANTE e CALDAS, 1999).

$\mathrm{O}$ grande número de fatores ambientais que podem afetar a saúde humana é um indicativo da complexidade das interações existentes e da amplitude de ações necessárias para melhorar os fatores ambientais determinantes da saúde (RIBEIRO, 2004).

Vários autores têm evidenciado a intrínseca relação entre situação de saúde e saneamento ambiental. As variáveis mais utilizadas para expressar condições de saneamento são abastecimento de água e esgotamento sanitário (BRASIL, 2010).

Mas essas variáveis vêm sendo cada vez mais ampliadas. A Lei Federal 11.445 de 2007, em seu art. $3^{\circ}$, define (BRASIL, 2007):

I - saneamento básico: conjunto de serviços, infra-estruturas e instalações operacionais de:

a) abastecimento de água potável: constituído pelas atividades, infra-estruturas e instalações necessárias ao abastecimento público de água potável, desde a captação até as ligações prediais e respectivos instrumentos de medição;

b) esgotamento sanitário: constituído pelas atividades, infra-estruturas e instalações operacionais de coleta, transporte, tratamento e disposição final adequados dos esgotos sanitários, desde as ligações prediais até o seu lançamento final no meio ambiente;

c) limpeza urbana e manejo de resíduos sólidos: conjunto de atividades, infra-estruturas e instalações operacionais de coleta, transporte, transbordo, tratamento e destino final do lixo doméstico e do lixo originário da varrição e limpeza de logradouros e vias públicas;

d) drenagem e manejo das águas pluviais urbanas: conjunto de atividades, infra -estruturas e instalações operacionais de drenagem urbana de águas pluviais, de transporte, detenção ou retenção para o 
amortecimento de vazões de cheias, tratamento e disposição final das águas pluviais drenadas nas áreas urbanas;

Se a universalização da rede de abastecimento de água, coleta de esgoto e de manejo de resíduos sólidos constitui parâmetro mundial de qualidade de vida já alcançado em grande parte dos países mais ricos, no Brasil a desigualdade verificada no acesso da população a esses serviços ainda constitui o grande desafio posto ao Estado e à sociedade em geral nos dias atuais (IBGE, 2011).

Estima-se que $80 \%$ de todas as moléstias, e mais de um terço dos óbitos dos países em desenvolvimento, sejam causados pelo consumo de água contaminada, sendo os esgotos e excrementos humanos causas importantes dessa deterioração da qualidade da água nesses países (FILHO et al., 2010).

\section{Abastecimento de água}

Segundo a FUNASA (BRASIL, 2007), sob o aspecto sanitário e social, o abastecimento de água visa, fundamentalmente, a controlar e prevenir doenças, implantar hábitos higiênicos na população como, por exemplo, a lavagem das mãos, o banho e a limpeza de utensílios e higiene do ambiente, facilitar a limpeza pública, facilitar as práticas desportivas, propiciar conforto, bem-estar e segurança e aumentar a esperança de vida da população.

Os riscos para a saúde relacionados com a água podem ser distribuídos em duas categorias (BRASIL, 2007):

- riscos relacionados com a ingestão de água contaminada por agentes biológicos (bactérias, vírus, e parasitos), pelo contato direto, ou por meio de insetos vetores que necessitam da água em seu ciclo biológico;

${ }^{\circ}$ riscos derivados de poluentes químicos e radioativos, geralmente efluentes de esgotos industriais, ou causados por acidentes ambientais.

A contaminação das águas por esgoto doméstico, que contém microrganismos patogênicos (bactérias, vírus e protozoários), faz com que ocorram casos de doenças de veiculação hídrica, como gastrenterites, febre tifoide, hepatite e cólera, que podem ser adquiridas com a ingestão destas águas (PHILIPPI JR. et al., 2004).

\section{Esgotamento Sanitário}

É grande o número de doenças cujo controle está relacionado com o destino inadequado dos dejetos humanos. Entre as principais estão ancilostomíase, ascaridíase, amebíase, cólera, diarréia infecciosa, disenteria bacilar, esquistossomose, estrongiloidíase, febre tifóide, febre paratifóide, salmonelose, teníase e cisticercose (BRASIL, 2007).

A transmissão destas doenças se dá pelo contato direto da pele com o solo contaminado por fezes de portadores de parasitoses, pelo contato direto da pele com coleções de água contaminada, pela ingestão de alimentos e água contaminados diretamente pelos dejetos ou por vetores (BRASIL, 2007).

\section{Resíduos Sólidos}

Muitos autores consideram o mau acondicionamento dos resíduos sólidos como fonte epidemiológica de doenças. Porém, do ponto de vista sanitário, não foi comprovada a relação direta do mesmo com a saúde. Contudo, existe uma contribuição indireta dos resíduos sólidos domésticos na transmissão de doenças, como por exemplo, por meio de vetores artrópodes (moscas, baratas e mosquitos) e roedores que encontram no lixo mal acondicionado, o que se torna uma fonte de alimentação, bem como uma condição ideal para sua proliferação (PALMEIRA et al., 2012).

Segundo a Constituição Federal de 1988, no art. 30, cabe ao poder público local a competência pelos serviços de limpeza pública, incluindo-se a coleta e a destinação dos resíduos sólidos urbanos. Portanto, cumpre ao município legislar, gerenciar e definir o sistema de saneamento básico local. Além disso, segundo o art. 182 da Constituição Federal, o município deve estabelecer as políticas de desenvolvimento urbano, ordenando o pleno desenvolvimento das funções sociais e garantindo o bem-estar de seus habitantes (PHILIPPI JR. et al., 2004).

\section{Drenagem Urbana}

"O sistema de drenagem de um núcleo habitacional é o mais destacado no processo de expansão urbana, ou seja, o que mais facilmente comprova a sua ineficiência, imediatamente após as precipitações significativas, trazendo transtornos à população quando causa inundações e alagamentos. Além desses problemas gerados, também propicia o aparecimento de doenças como 
a leptospirose, diarreias, febre tifoide e a proliferação dos mosquitos anofelinos, que podem disseminar a malária. E, para isso tudo, estas águas deverão ser drenadas e como medida preventiva adotar-se um sistema de escoamento eficaz que possa sofrer adaptações, para atender à evolução urbanística, que aparece no decorrer do tempo" (BRASIL, 2007).

Sob o ponto de vista sanitário, a drenagem visa principalmente desobstruir os cursos d'água dos igarapés e riachos, para eliminação dos criadouros (formação de lagoas) combatendo, por exemplo, a malária e a não propagação de algumas doenças de veiculação hídrica (BRASIL, 2007).

\section{Ambiental}

Doenças relacionadas ao Saneamento

A FUNASA (BRASIL, 2010) enumera e classifica as doenças relacionadas ao saneamento ambiental inadequado em a) infecções relacionadas à água , b) infecções relacionadas às excretas e c) enfermidades infectoparasitárias relacionadas com o lixo, conforme (Tabelas 1, 2 e 3).

A classificação ambiental de infecções relacionadas à água possui quatro categorias de transmissão: 1. Feco-oral; 2. Relacionadas com a higiene; 3 . Baseada na água; 4. Através de inseto vetor. Estas doenças são passíveis de controle, ou pelo menos podem ser influenciadas, através do abastecimento de água.

A classificação de doenças relacionadas às excretas reúne aquelas causadas por patógenos transmitidos por excretas humanos, normalmente as fezes, e possibilita a compreensão dos efeitos de medidas sanitárias relacionadas com a eliminação de excretas.

A disposição inadequada de lixo permite a disseminação de microorganismos através de mos-

Tabela 1- Infecções relacionadas com a água.

\begin{tabular}{ll}
\hline Categoria & Infecção \\
\hline 1. Feco-oral (ingestão de água ou contato & Diarreias e disenterias \\
com a água) & Febres entéricas \\
& Poliomielite \\
& Hepatite A \\
& Leptospirose \\
2. Relacionadas com a higiene & Doenças infecciosas da pele \\
a) Infecções da pele e dos olhos & Doenças infecciosas dos olhos \\
b) Outras & Tifo transmitido por pulgas \\
& Febre recorrente transmitida por pulgas \\
3. Baseada na água & Esquistossomose \\
a) Por penetração na pele & Difilobotríase e outras infecções por \\
b) Por ingestão & helmintos \\
4. Transmissão por inseto vetor & Doença do sono \\
a) Picadura próxima à água & Filariose \\
b) Procriam na água & Malária \\
& Febre amarela \\
& Dengue \\
& Leishmaniose \\
\hline
\end{tabular}

Fonte: Fundação Nacional de Saúde - FUNASA, 2010. 
Tabela 2- Infecções relacionadas com as excretas

\begin{tabular}{|c|c|c|}
\hline Categoria & Infecção & $\begin{array}{l}\text { Via dominante de } \\
\text { Transmissão }\end{array}$ \\
\hline $\begin{array}{l}\text { 1. Doenças } \\
\text { feco-orais não bacterianas }\end{array}$ & $\begin{array}{l}\text {-Enterobíase } \\
\text {-Infecções enteroviróticas } \\
\text {-Himenolepíase } \\
\text {-Amebíase } \\
\text {-Giardíase } \\
\text {-Balantidíase }\end{array}$ & $\begin{array}{l}\text {-Pessoal } \\
\text {-Doméstica }\end{array}$ \\
\hline $\begin{array}{l}\text { 2. Doenças feco-orais } \\
\text { bacterianas }\end{array}$ & $\begin{array}{l}\text {-Febres entéricas: tifoide e } \\
\text { paratifoide } \\
\text { - Diarreias e disenterias }\end{array}$ & $\begin{array}{l}\text { - Pessoal } \\
\text { - Doméstica } \\
\text { - Água } \\
\text { - Alimentos }\end{array}$ \\
\hline 3. Helmintos do solo & $\begin{array}{l}\text {-Ascaridíase } \\
\text {-Tricuríase } \\
\text {-Ancilostomíase } \\
\text {-Estrongiloidíase }\end{array}$ & $\begin{array}{l}\text { - Jardins } \\
\text { - Campos } \\
\text { - Culturas agrícolas }\end{array}$ \\
\hline 4. Teníases & -Teníases & $\begin{array}{l}\text { - Jardim } \\
\text { - Campos } \\
\text { - Pastagem }\end{array}$ \\
\hline $\begin{array}{l}\text { 5. Helmintos } \\
\text { Hídricos }\end{array}$ & $\begin{array}{l}\text { Esquistossomose e outras } \\
\text { doenças provocadas por } \\
\text { helmintos }\end{array}$ & - Água \\
\hline $\begin{array}{l}\text { 6. Doenças transmitidas por } \\
\text { insetos }\end{array}$ & $\begin{array}{l}\text { Filariose e todas as } \\
\text { infecções mencionadas nas } \\
\text { categorias } 1 \text { a } 5 \text {, dos quais } \\
\text { moscas e baratas podem ser } \\
\text { vetores }\end{array}$ & $\begin{array}{l}\text { - Vetores locais } \\
\text { contaminados por fezes, nos } \\
\text { quais insetos procriam }\end{array}$ \\
\hline
\end{tabular}


Tabela 3- Enfermidades infectoparasitárias relacionadas com o lixo

\begin{tabular}{ll}
\hline Categoria & Doenças \\
\hline 1. Doenças relacionadas com os insetos & Infecções excretadas transmitidas por \\
vetores & moscas ou baratas \\
& Filariose \\
& Tularemia \\
2. Doenças relacionadas com os vetores & Peste \\
roedores & Leptospirose \\
& Demais doenças relacionadas à moradia, à \\
& água e aos excretas, cuja transmissão ocorre \\
& por roedores. \\
\hline
\end{tabular}

Fonte: Fundação Nacional de Saúde - FUNASA, 2010.

cas, mosquitos e ratos, permitindo a transmissão de infecções por insetos vetores e por roedores.

Permeando os fatores água, esgotamento sanitário, lixo e drenagem urbana têm-se as zoonoses como fator ambiental que coloca em risco a saúde da população. O termo zoonoses pode ser definido como infecções ou doenças transmitidas naturalmente entre animais vertebrados e o homem. É preciso ressaltar que as zoonoses podem se constituir em infecções oportunistas extremamente graves em indivíduos imunocomprometidos (FERREIRO et al., 2007).

Segundo dados da Organização Mundial da Saúde, $60 \%$ dos patógenos humanos são zoonóticos, $75 \%$ das enfermidades emergentes humanas são de origem animal e $80 \%$ dos patógenos que poderiam ser usados em bioterrorismo também são de origem animal (CRMV, 2010).

Questões relativas a populações de cães como animais de estimação apresentam grande importância por serem mantidos em estreito contato com seres humanos. Segundo MATOS et al. (2002), no que diz respeito à área da saúde, entre vários aspectos, pode ser salientada a sua participação na cadeia epidemiológica de diversas zoonoses como a raiva, a leishmaniose visceral e o complexo larva migrans visceral/toxocariose. Os cães podem ainda desempenhar papel de reservatório de agentes etiológicos oportunistas, com implicações para pessoas imunodeprimidas.

\section{METODOLOGIA}

O estudo foi de abordagem qualitativa, do tipo documental, utilizando dados secundários, oriundos das notificações compulsórias recebidas pela Vigilância Epidemiológica de Capão do Leão/RS e registradas no SINAN - Sistema de Informação de Agravos de Notificação - referentes aos anos de 2010, 2011 e 2012. Foram selecionados dentre o total de agravos notificados aqueles referentes a doenças listadas pela FUNASA, além do atendimento antirrábico. Quanto aos fatores ambientais, o diagnóstico constante no Plano de Saneamento do município foi o instrumento utilizado, além de dados de infraestrutura divulgados pelo IBGE - Instituto Brasileiro de Geografia e Estatística. Além destes, foram utilizados outros documentos pertinentes à pesquisa, como atas e notícias publicadas em meio eletrônico.

\section{RESULTADOS E DISCUSSÃO}

Segundo os relatórios oriundos do SINAN, cedidos pela Vigilância em Saúde de Capão do Leão, a ocorrência de agravos relacionados ao saneamento ambiental nos anos de 2010, 2011 e 2012 foi a seguinte: em 2010, de um total de 258 notificações, 46,9\% (121) foram referentes a Atendimento Antirrábico, $14,7 \%$ (38) a Hepatites Virais; 5,8\% (15) correspondente a Leptospirose. No ano de 2011, foram notificados 238 agravos, dos quais 47,9\% (144) Atendimento Antirrábico, $7,6 \%$ (18) Hepatites Virais e 0,8\% (2) Leptospirose. Em 2012 foram registradas 269 notificações, sendo 64,7\% (174) Atendimento Antirrábico, 0,74\% (2) 
Hepatites Virais e não houve notificação de casos de Leptospirose.

De acordo com o Censo 2010, realizado pelo IBGE, no município de Capão do Leão 6.660 domicílios particulares permanentes em áreas urbanas estão ligados à rede de abastecimento de água, o que corresponde a 20.705 pessoas atendidas. Destes, 69,1\% (4.602) declararam existir esgoto a céu aberto no entorno e $5,9 \%$ (392) a existência de lixo acumulado nos logradouros. A ausência de estrutura de drenagem pluvial, como bocas de lobo e bueiros foi relatada por $93,7 \%$ (6.238) dos domicílios.

A Prefeitura, em seu Plano de Saneamento Básico, diz que "o município não possui tratamento de esgoto. Outros sistemas existentes e individuais para o tratamento do esgoto são as fossas sépticas e os sumidouros, que deveriam ser obrigatórios para aprovação de projetos de construção civil". No mesmo documento consta que a coleta de lixo é feita periodicamente pelo executivo, sendo coletados aproximadamente 200 ton/mês, e destinado ao aterro sanitário privado localizado no município de Candiota, distante $140 \mathrm{~km}$ de Capão do Leão (CAPÃO DO LEÃO, 2011).

Por meio da análise dos dados obtidos, pode-se dizer que a população de Capão do Leão está exposta, principalmente, a zoonoses e doenças relacionadas às excretas e de transmissão via feco-oral ${ }^{2}$.

O alto índice de atendimentos antirrábicos realizados no município expõe a realidade do grande número de animais errantes, principalmente cães, presentes nas ruas, pois esse atendimento se dá a partir de um episódio de agressão animal. Assim, as pessoas podem adquirir zoonoses não só pelo contato com fezes contaminadas, mas pela mordedura ou arranhadura desses animais (CAPÃO DO LEÃO, 2013).

No ano de 2012 foram encontrados na zona rural do município focos de morcegos portadores do vírus da raiva (DIÁRIO LEONENSE, 2012). Uma grande população canina presente nas ruas aumenta as chances de que as pessoas contraiam a doença, caso esta chegue à zona urbana. Aumenta também a população de carrapatos, que tem cães como hospedeiros, e podem transmitir a febre maculosa ${ }^{3}$.

2. Rota de transmissão de doenças, na qual estas são passadas quando patógenos em partículas fecais de um hospedeiro são introduzidos na cavidade oral de outro hospedeiro potencial. http://www.dicio. com.br/

3. Zoonose transmitida por picada de carrapatos infectados por Rickettsia rickettsii. Pode ocorrer transmissão através da contaminação de lesões na pele pelo esmagamento do carrapato (CRMV, 2010).
Tanto pelos dados obtidos pelo Censo 2010 quanto pelo Plano de Saneamento Básico constata-se a ausência de tratamento de esgoto no munícipio. Mas a presença de esgoto à céu aberto em mais de $50 \%$ dos domicílios constatada pelo IBGE demonstra uma situação ainda mais grave.

O esgoto doméstico é lançado nas ruas, e escoa pelo precário sistema de drenagem pluvial, constituindo um sistema misto (CAPÃO DO LEÃO, 2011). Esta situação favorece a proliferação de animais sinantrópicos, vetores de inúmeras doenças. Além disso, em caso de enchente, a população entra em contato direto com o esgoto, ficando sujeita a contrair doenças como a diarreia e a leptospirose, que está presente nos registros do SINAN, além da hepatite A. O Sistema de Informação de Agravos de Notificação não especifica as hepatites virais por tipos.

Por outro lado, constata-se que a grande maioria da população tem suas residências abastecidas com água potável e coleta de lixo periódica. Esses são fatores que auxiliam na redução do número de doenças adquiridas por meio de fatores ambientais.

Pode-se verificar, ainda, um baixo índice de notificações recebidas pela Vigilância em Saúde. As notificações são oriundas exclusivamente da rede pública de saúde municipal, pois não é realizada busca ativa nos estabelecimentos particulares de saúde de Capão do Leão ou Pelotas, município onde muitos moradores procuram atendimento médico.

\section{CONSIDERAÇÕES FINAIS}

Com este estudo foi possível verificar que, assim como na maioria dos municípios brasileiros, em Capão do Leão o saneamento ambiental ainda está distante do ideal, pois faltam itens de infraestrutura para a prevenção de doenças relacionadas a fatores ambientais, inclusive previstos pela legislação vigente no país. O município carece de investimentos não só em obras de saneamento, mas em educação ambiental e em saúde para a população.

O Plano de Saneamento Básico Municipal já foi estruturado, o que deve contribuir para avanços no saneamento ambiental nos próximos anos. Mas ainda faltam ações relativas ao grande número de animais errantes nas ruas, realidade presente em toda a região, e que expõe a população a inúmeras doenças.

Por fim, é necessário haver um claro entendimento das relações fundamentais entre as condi- 
ções ecológicas, culturais e de saúde humana para que se desenvolva um meio ambiente saudável, com equidade social e desenvolvimento sustentável, fatores indispensáveis para a melhoria e manutenção da saúde humana (PHILIPPI JR. et al., 2004).

Este estudo faz esse levantamento no sentido de contribuir para um planejamento em saúde, visando as principais necessidades da população com vistas a um equilíbrio entre as atividades humanas e o meio ambiente, para que assim se possa vislumbrar uma efetiva qualidade de vida. $\mathrm{O}$ estudo será levado a conhecimento das autoridades locais, com intuito de discutir estes aspectos junto a Prefeitura e o Conselho Municipal de Saúde.

\section{REFERÊNCIAS}

BORJA, P. C. e MORAES, L. R. S. Indicadores de saúde ambiental com enfoque para a área de saneamento. Parte 1 - aspectos conceituais e metodológicos. Engenharia Sanitária e Ambiental. v. 8 n. 1, Jan-Mar 2003 e n. 2, Abr-Jun 2003.

BRASIL. Caderno setorial de recursos hídricos: saneamento. Ministério do Meio Ambiente. Secretaria de Recursos Hídricos. Brasília: MMA, 2006.

BRASIL. Manual de saneamento. Fundação Nacional de Saúde. 3. ed. rev. Brasília: Fundação Nacional de Saúde, 2006. 408 p.

BRASIL. Lei n. 11.445, de 5 de Janeiro de 2007. Estabelece diretrizes nacionais para o saneamento básico; altera as Leis nos 6.766, de 19 de dezembro de $1979,8.036$, de 11 de maio de 1990, 8.666, de 21 de junho de 1993, 8.987, de 13 de fevereiro de 1995; revoga a Lei no 6.528, de 11 de maio de 1978; e dá outras providências. Diário Oficial da União. Seção 1. 08 Jan 2007. p. 3.

BRASIL. Impactos na saúde e no Sistema Único de Saúde decorrentes de agravos relacionados a um saneamento ambiental inadequado. Fundação Nacional de Saúde. Brasília: Fundação Nacional de Saúde, 2010. 246 p.

BRILHANTE, O. M. e CALDAS, L. Q. A. Gestão e avaliação de risco em saúde ambiental. Rio de Janeiro: Editora FIOCRUZ, 1999. 155 p.

CAPÃO DO LEÃO. Prefeitura Municipal. Secretaria Municipal de Obras, Urbanismo e Meio Ambiente. Plano de Saneamento Básico Municipal de Capão do Leão. Capão do Leão, 2011, 106 p.

CAPÃO DO LEÃO. Câmara Municipal do Capão do Leão. Ata da Sessão Ordinária 14/2013. Disponível em <http://www.camaracapaodoleao.rs.gov.br/ acesso/admin/pdfs/RcRipKwqKJPf.pdf>. Acesso em: 15 Ago. 2013.

CRMV. Conselho Regional de Medicina Veterinária. Manual de Zoonoses. Programa de Zoonoses Região Sul. Volume I. 2 ${ }^{\mathrm{a}}$ Edição. 2010.

DIÁRIO LEONENSE. Rural: Após morte de bovinos por raiva, Estado busca focos do morcego transmissor. Capão do Leão, 2012. Disponível em $<$ http://www.diarioleonense.com/2012/10/rural -apos-morte-de-bovinos-por-raiva.html> . Acesso em: 15 Ago. 2013.

FERREIRO L.; SANCHES, E. M. C.; SPANAMBERG, A.; FERREIRA, R. R.; MACHADO M. L. S.; ROEHE, C.; PEREIRA, S. A.; SCHUBACH T. M. P.; SANTURIO, J. M. Zoonoses micóticas em cães e gatos. Acta Scientiae Veterinariae. v. 35, supl. 2: s296-s299, 2007. ISSN 1679-9216.

FILHO, J. K. M. A.; JUSTINO, L. G.; FILHO, L. P. M.; NETO, M. L. R.; JÚNIOR, J. B. Relação Saúde Ambiental/Saúde Humana: (Re)Conhecendo o Cenário do Programa Nacional de Vigilância em Saúde Ambiental. Neurobiologia, v. 73. Jul-Set 2010.

IBGE. Instituto Brasileiro de Geografia e Estatística. CENSO 2010. Disponível em <http://censo2010. ibge.gov.br/>. Acesso em: 23 mai. 2013.

IBGE. Atlas de saneamento 2011. Ministério do Planejamento, Orçamento e Gestão. Instituto Brasileiro de Geografia e Estatística - IBGE. Diretoria de Geociências. Rio de Janeiro, 2011.

MATOS, M. R.; ALVES, M. C. G. P.; REICHMANN, M. L. A. B.; DOMINGUEZ, M. H. S. Técnica Pasteur São Paulo para dimensionamento de população canina. Cad. Saúde Pública. v. 18: 1423-1428, Set-Out. Rio de Janeiro, 2002.

PALMEIRA, C.; SANTOS, M.; CRUZ, R. M. V.; SANTOS, L. O. A influência dos resíduos sólidos na saúde: estudo de caso sobre catadores socialmente organizados. Revista FIBRA \& Ciência, n. 7, Jun. de 2012.

PHILIPPI JR., A.; ROMÉRO, M. A.; BRUNA, G. C. Curso de Gestão Ambiental. Coleção Ambiental. 
Barueri, SP: Editora Manole, 2004. ISBN 85-2042055-9

RIBEIRO, Helena. Saúde Pública e Meio Ambiente: evolução do conhecimento e da prática, alguns aspectos éticos. Saúde e Sociedade. v.13, n.1, p.7080, Jan-Abr 2004. 